\title{
Particle Intiated Breakdown Inside Gas Insulated Switchgear for Various Gases Mixtures
}

\author{
Sayed A. Ward ${ }^{1}$, M. A. Abd Allah², and Amr A. Youssef ${ }^{3}$ \\ Electrical Engineering Department, Faculty of Engineering at Shoubra, \\ Benha University, Cairo, Egypt \\ 3 eng_power_amr2011@yahoo.com
}

\begin{abstract}
SF}_{6}$ gas insulated switchgear plays an important role in electric power networks all over the world due to its merits as compared to traditional air insulated switchgear.The mixtures composed of a strongly electronegative gases with high dielectric strength such as $\mathrm{SF}_{6}$ and two ordinary gases such as $\mathrm{N}_{2}$ and Air or $\mathrm{CO}_{2}$ and Air with a various fractional concentrations are used in this paper to reduce the gas price and liquefaction temperature. From this point of view, various types of gas mixtures are used inside gas insulated switchgear (GIS) to give a higher dielectric strength. In this paper, the Finite Elements Method (FEM) is used to evaluate the potential and electric field distributions on and around contaminating filamentary wire particle at two positions, first is resting on the earthed plate and second is hovering inside the gap. The effects of particle dimensions such as (length, radius) and gap spacing on the electric field values are also studied. The breakdown voltage calculations under uniform field in case of clean gap and non-uniform field in case of gap with particle contamination are studied. The effects of gas pressure, $\mathrm{SF}_{6}$ gas concentration in mixture, gap spacing and particle dimensions on the breakdown voltage calculations are also studied.
\end{abstract}

Keywords: Mixtures, GIS, FEM, Electric Field, Breakdown Voltage.

\section{Introduction}

$\mathrm{SF}_{6}$ has been widely used as insulation media for gas insulated switchgear (GIS) and gas insulated transmission line (GIL), due to its excellent insulation and arc quenching properties. Although the $\mathrm{SF}_{6}$ gas has superior dielectric properties, $\mathrm{SF}_{6}$ gas made an issue of environmental influence due to its high global warming potential $(\mathrm{GWP}=23900)$. Thus the development of an alternative gas or gas mixtures having much lower GWP is strongly required. Mixtures composed of a strongly electronegative gas of high dielectric strength such as $\mathrm{SF}_{6}$ and two ordinary gases such as $\mathrm{N}_{2}$ and air or $\mathrm{CO}_{2}$ and air with a various concentrations are used in this work.

The presence of contaminating particles lowered the dielectric strength of the gas sharply. Some studies were carried out both Theoretically [1-6] and experimentally [7-11] to determine the role of single contaminating particles in initiating breakdown in gaseous insulation under pure $\mathrm{SF}_{6}$ or $\mathrm{SF}_{6}$ gas with one ordinary gas such as $\mathrm{CO}_{2}$ or $\mathrm{N}_{2}$. The determination of the breakdown voltage in the gas requires the knowledge of the potential and field distribution on and around the charged particle surface. So in this paper, the electric potential and field distribution are studied between two parallel plates with a wire-shaped (filamentary) particle when it rested on the earthed plate and hovering in the gap. The finite element method (FEM) has been used throughout the calculations in this paper, for its favorable accuracy, when applied to high voltage problems.

\section{Electric Field Calculations}

The electric field is calculated with using the Finite Element Method (FEM) throughout this work. The Finite Element Method Magnetics (FEMM) Package is used to simulate the

Received: May $20^{\text {th }}, 2012$. Accepted: August $8^{\text {th }}, 2012$ 
problems and to calculate the electric field inside the GIS. FEMM is a finite element package for solving 2D planar and axi-symmetric problems in electrostatics and in low frequency magnetic [12].

The FEMM Version 4.2 is used throughout the work in this paper for computation the voltage and the electric field distributions around the contaminating particles.

The electric field and voltage distributions on and around filamentary (wire) contaminating particle lies on the earthed electrode of two parallel electrodes will be presented. Also, the electric field distributions around hovering contaminating particles between the two parallel plates will be computed.

\section{Electrostatic Modeling of Wire Particle Contamination}

A. When The Particle is on Earthed Electrode

Figure 1 shows two parallel plates configuration with filamentary wire contaminating particles resting on the earthed plate. The gap between the plates is taken as $20 \mathrm{~mm}$.

Where, $\mathrm{L}$ is the particle length, $\mathrm{r}$ is hemispherical radius of the particle, $\mathrm{G}$ is the gap between two parallel plates and $\mathrm{Gu}$ is the upper gap space from upper tip of the particle up to upper plate.

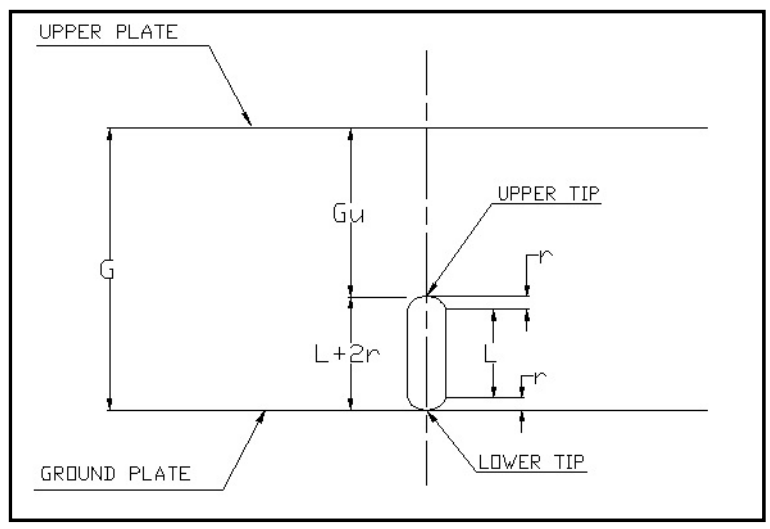

Figure 1. Two parallel plates configuration with filamentary wire contaminating particle resting on earthed electrode

\section{(a) For wire particle of $2 \mathrm{~mm}$ length and of $0.2 \mathrm{~mm}$ radius}

The potential distribution along gap between two parallel plates with the wire contaminating particle, resting on earthed plate is shown in Figure 2. It can be observed that the voltage decreases gradually from 1volt at the upper plate through the gap until it reaches zero at the ground plate. Figure 3 shows the electric field distribution along gap between two parallel plates with wire contaminating particle resting on earthed plate. It can be observed that the electric field is maximum value at upper tip of earthed wire particle and minimum value at lower tip of it. Figure 4 shows the electric field distribution around wire contaminating particle resting on earthed electrode. It can be observed that the electric field increases gradually from zero at the lower tip of the wire particle until it reaches to maximum value, about $445.2 \mathrm{~V} / \mathrm{m}$, at the upper tip of it. 


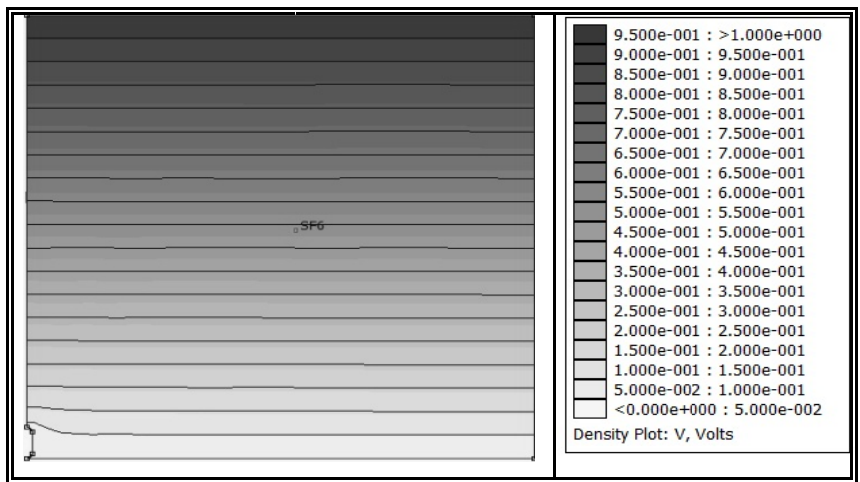

Figure 2. Potential distribution along gap between two parallel plates with wirecontaminating particle resting on earthed electrode

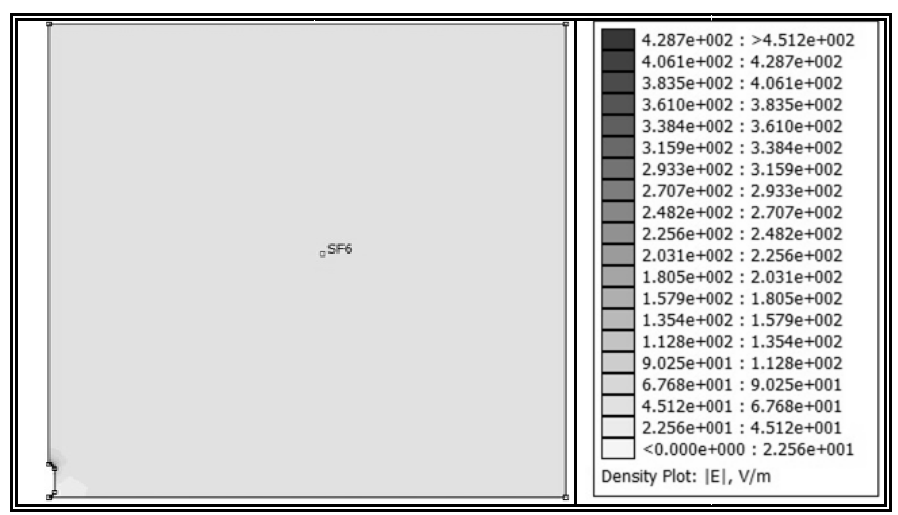

Figure 3. Electric field distribution along gap between two parallel electrodes with wirecontaminating particle resting on earthed electrode

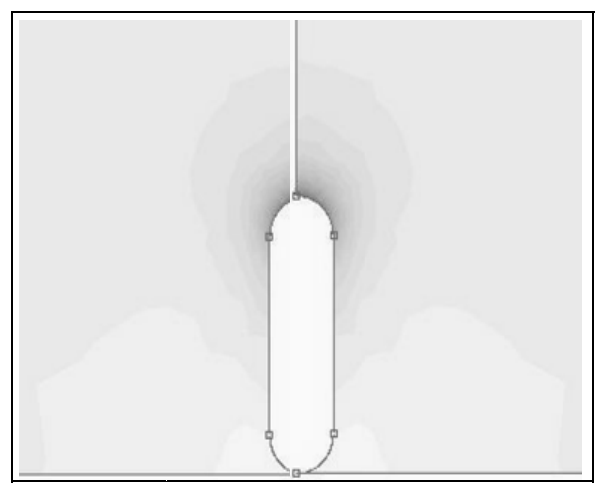

Figure 4. Electric field distribution around wire contaminating particle resting onearthed electrode

Figure 5 shows the electric potential distribution along gap from upper tip of wire particle up to upper plate. It can be observed that the voltage increases gradually from zero at ground electrode until reach to 1 volt at upper plate. Figure 6 shows magnitude, normal and tangential components of electric field distribution along gap from upper tip of wire particle up to upper plate. It can be observed that normal component of electric field is around zero. The tangential component of electric field is maximum value $(\approx 445.21 \mathrm{~V} / \mathrm{m})$ at upper tip of wire particle and 
decreases gradually as far from it and then approximately become constant $(\approx 50.11 \mathrm{~V} / \mathrm{m})$ along the remainder gap from $4 \mathrm{~mm}$ from upper tip of wire particle up to upper plate. Figure 7 shows magnitude, normal and tangential components of electric field distribution along surface of wire particle. It can be observed that the tangential component of electric field is around zero and the normal component of it increases gradually from zero until reach to maximum value at upper tip through negative side, so mathematically, the magnitude of electric field is also increases from zero to $445.20 \mathrm{~V} / \mathrm{m}$ at upper tip of wire particle though positive side .

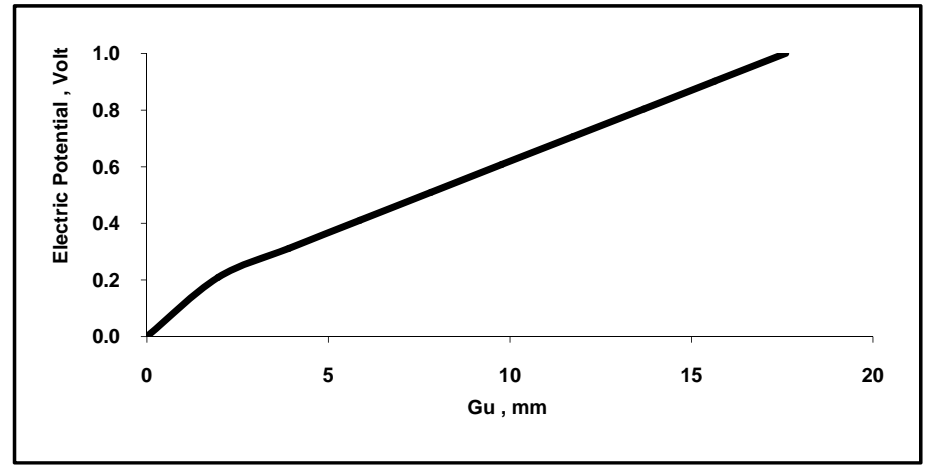

Figure 5. Electric potential distribution along gap from upper tip of wire particle up to upper plate

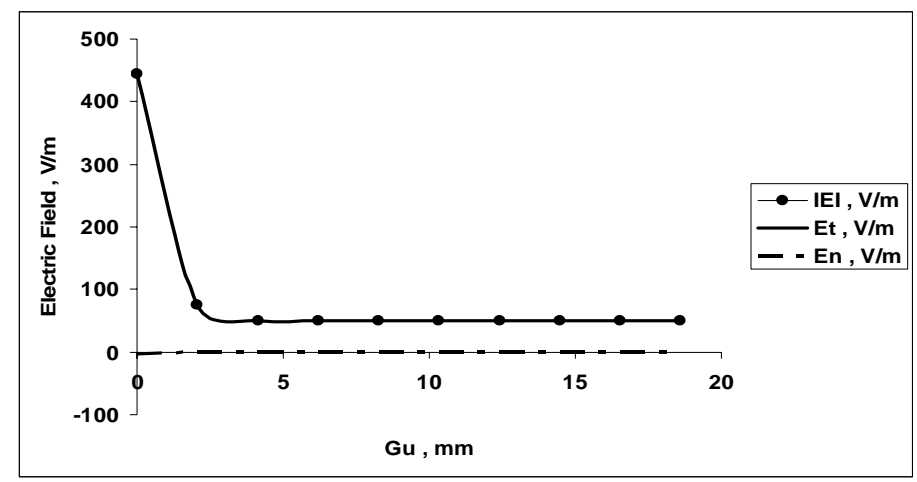

Figure6. Electric field distribution along gap from upper tip of wire particle up to upper plate

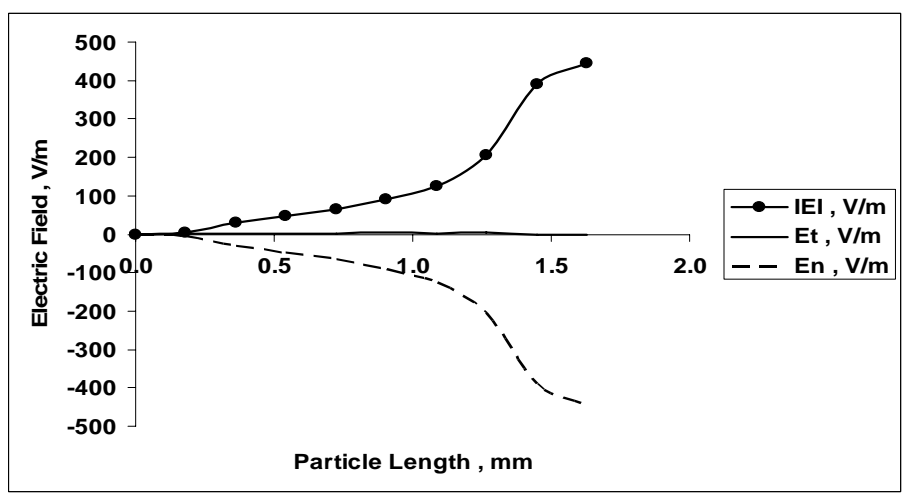

Figure 7. Electric field distribution along surface of wire particle 
(b) Effect of particle length on the electric field values

The variation of the electric field value at the upper tip of the wire particle with respect to the particle length is shown in Figure 8. It can be observed that as the particle length increases from $1 \mathrm{~mm}$ to $5 \mathrm{~mm}$, the electric field at upper tip of the wire particle increases from about $445.2 \mathrm{~V} / \mathrm{m}$ to about $1233.8 \mathrm{~V} / \mathrm{m}$.

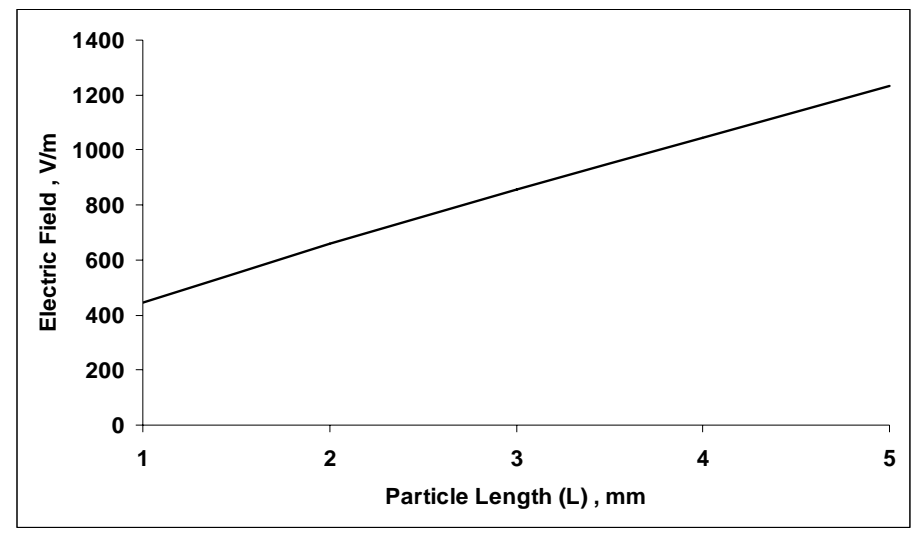

Figure 8. Electric Field at upper tip of wire particle with respect to Particle length

\section{(c) Effect of ratio $(L / r)$ on the electric field values}

Figure 9 shows the variation of the electric field value at the upper tip of the wire particle with respect to the ratio $(\mathrm{L} / \mathrm{r})$. It can be observed that as the ratio of $(\mathrm{L} / \mathrm{r})$ increases from 5 to 25 , the electric field at upper tip of the wire particle will increase from about $445.2 \mathrm{~V} / \mathrm{m}$ to about $1233.8 \mathrm{~V} / \mathrm{m}$.

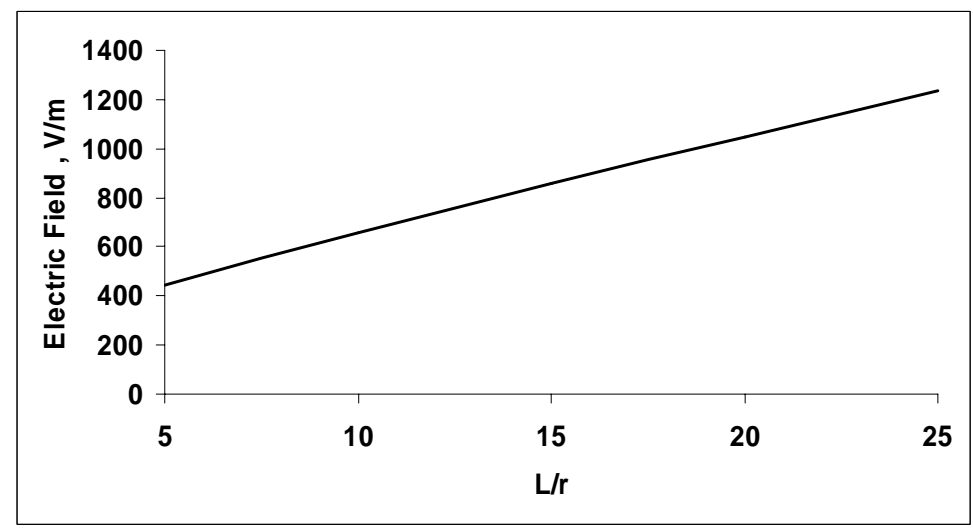

Figure 9. The electric field values at upper tip of wire particle as a function of the ratio $(\mathrm{L} / \mathrm{r})$

(d) Effect of wire particle radius on the electric field values

The effect of changing the wire particle radius on the electric field values at the upper tip of the wire particle is shown in Figure 10. The wire particle length is taken $2 \mathrm{~mm}$. As the wire particle radius increases from $0.1 \mathrm{~mm}$ to $0.5 \mathrm{~mm}$, the electric field at the upper tip of the particle decreases from about $1039 \mathrm{~V} / \mathrm{m}$ to about $402 \mathrm{~V} / \mathrm{m}$, i.e as the wire particle radius increases, the electric field decreases. 


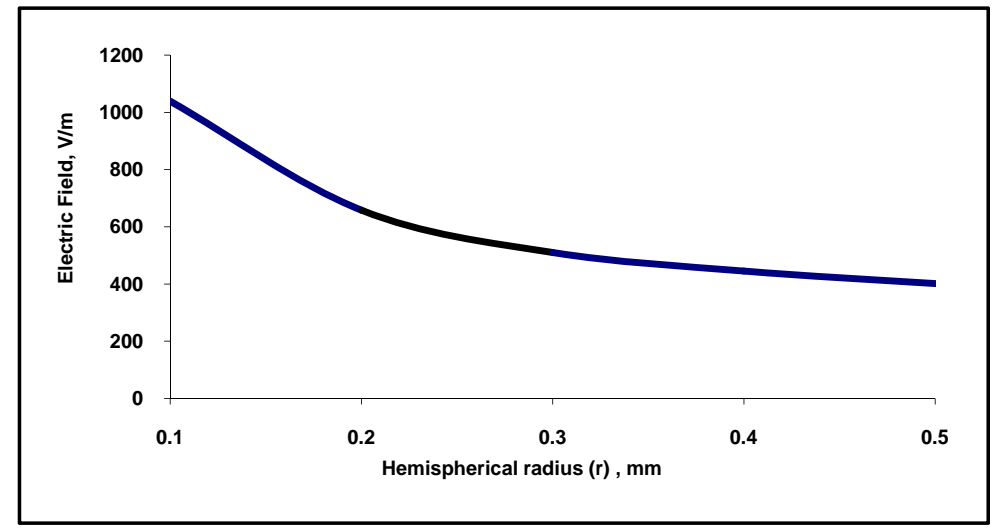

Figure 10. The electric field at upper tip of wire particle versus the particle radius

(e) Effect of gap spacing between plates on the electric field values

The effect of the gap spacing between the two parallel plates on the electric field at upper tip of the wire particle is shown in Figure 11. The wire particle length is taken as $2 \mathrm{~mm}$ and the wire particle radius as $0.2 \mathrm{~mm}$. It is noticed that as the gap spacing increases from $10 \mathrm{~mm}$ to $50 \mathrm{~mm}$, the electric field at upper tip of the wire particle decreases from about $1312.4 \mathrm{~V} / \mathrm{m}$ to about $261.6 \mathrm{~V} / \mathrm{m}$.

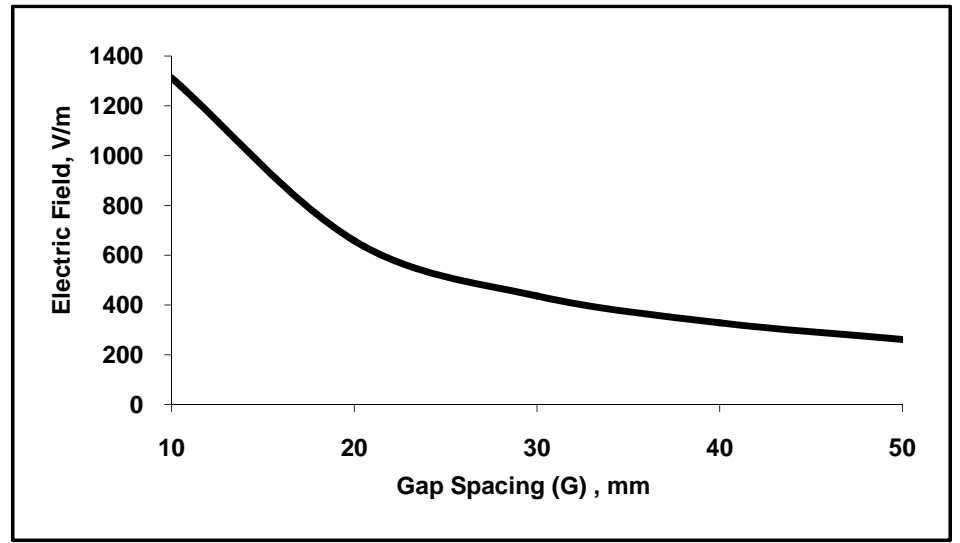

Figure 11. The electric field at upper tip of wire particle versus the gap spacingbetween two parallel plates

\section{B. When The Particle is Hovering Inside the Gap}

Figure 12 shows a wire particle hovering in the gap between two parallel plates. Figure 13 shows effect of changing of particle height above the ground plate on the electric field. The wire radius (r) is taken as $0.3 \mathrm{~mm}$, the wire length to radius ratio $(\mathrm{L} / \mathrm{r})$ as 15 and the gap spacing $(\mathrm{G})$ is $20 \mathrm{~mm}$. When the height of the wire particle (h) is zero, i.e. the particle is resting on the ground plate, the electric field at the lower tip of the wire particle is equal to zero but its value at the upper tip of wire particle is equal to about $850.8 \mathrm{~V} / \mathrm{m}$. As the particle height increases from $0 \mathrm{~mm}$ to $2 \mathrm{~mm}$, the electric field at the lower tip of the wire particle increases from $0 \mathrm{~V} / \mathrm{m}$ to about $525.0 \mathrm{~V} / \mathrm{m}$, while at the upper tip of the wire particle the field decreases from about $850.8 \mathrm{~V} / \mathrm{m}$ to about $501.2 \mathrm{~V} / \mathrm{m}$. When the particle height increases from $2 \mathrm{~mm}$ to $10 \mathrm{~mm}$, the electric field at the lower tip of the wire particle is slightly decreased from about $525.0 \mathrm{~V} / \mathrm{m}$ to about $504.7 \mathrm{~V} / \mathrm{m}$, while at the upper tip of the wire particle is slightly increased from about $501.2 \mathrm{~V} / \mathrm{m}$ to about $507.1 \mathrm{~V} / \mathrm{m}$. 


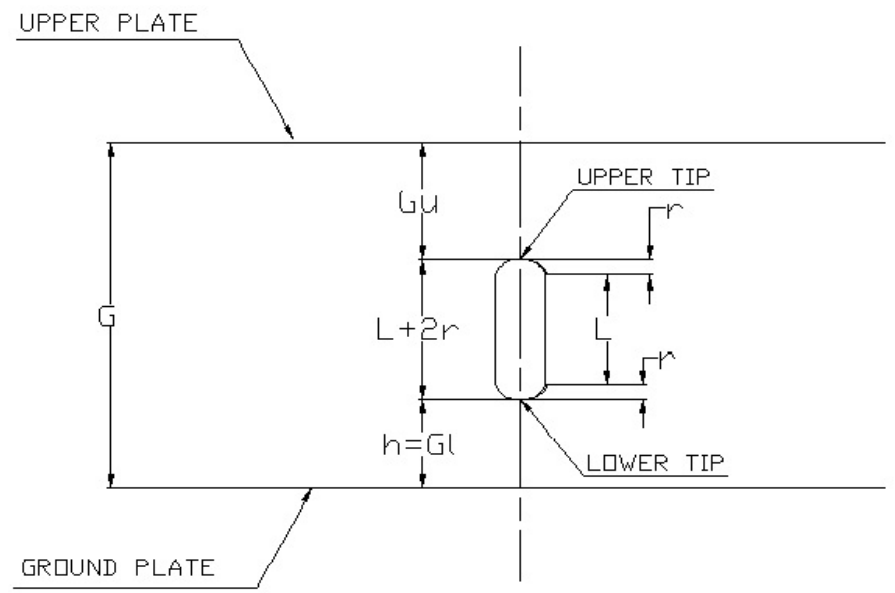

Figure 12. Two parallel electrodes configuration with filamentary wire contaminatingParticle hovering in the gap

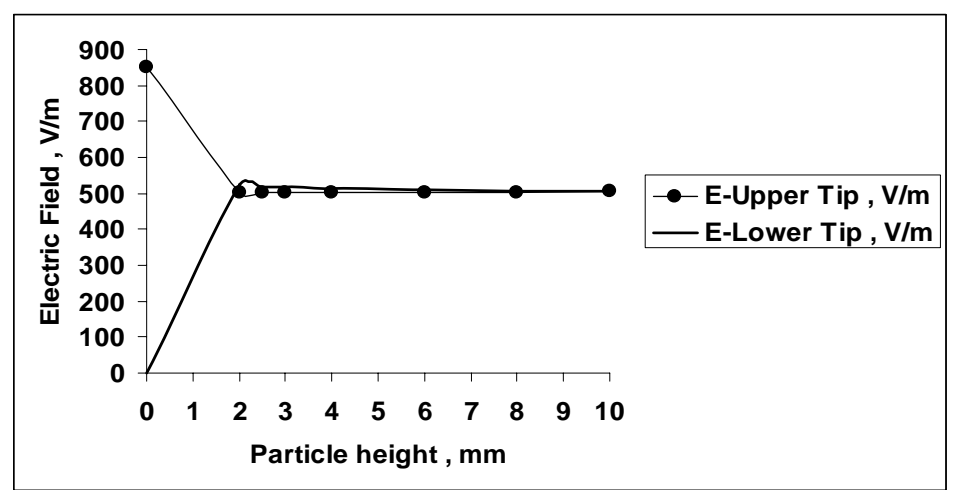

Figure 13. The electric field at the upper tip and the lower tip of the wire particle versusthe particle height above the ground plate

\section{Ionization Coefficients for $\mathrm{SF}_{6}$-Gas Mixtures}

In order to compute the breakdown voltages of $\mathrm{SF}_{6}$-gas mixtures, a knowledge of the effective ionization coefficient $\alpha=\alpha-\eta$ as a function of the electric field intensity (E) in the neighborhood of $\alpha=0$ is a prerequisite. The net ionization coefficients for $\mathrm{SF}_{6}$-gas mixtures $(\alpha)$ mix can be calculated from the values of $\alpha$ in pure gases. For pure Nitrogen the net ionization coefficients $\alpha$ can be approximated by [13];

$$
\frac{\bar{\propto}}{P}=66 \exp \left[\frac{-2.15}{E / P}\right]
$$

The measurements of the effective ionization coefficient $\alpha$ for $\mathrm{CO}_{2}$ has been summarized by Rein and can be approximated by the following equations[14] :

$$
\frac{\bar{\propto}}{P}=176.5 \exp \left[\frac{-2.565}{E / P}\right] \text { for } 0.2<=\mathrm{E} / \mathrm{P}<=0.28
$$




$$
\frac{\bar{\propto}}{P}=50.3 \exp \left[\frac{-1.515}{E / P}\right] \quad \text { for } 0.28<\mathrm{E} / \mathrm{P}<=100
$$

For air, the ionization coefficients can be approximated by [15],

$$
\begin{array}{ll}
\frac{\bar{c}}{P}=22(E / P-0.244)^{2} & \text { for } 0.244<\mathrm{E} / \mathrm{P}<=0.5 \\
\frac{\propto}{P}=15.8114(E / P-0.244)^{1.75} & \text { for } 0.5<\mathrm{E} / \mathrm{P}<=1.2
\end{array}
$$

For pure $\mathrm{SF}_{6}, \quad / \mathrm{P}$ can be expressed as [16],

$$
\frac{\bar{\propto}}{P}=27(E / P-0.8775)
$$

In Eqs. (1) through (6), $\mathrm{P}$ is the gas pressure in $\mathrm{kPa}, \quad / \mathrm{P}$ is given in $(\mathrm{cm} \cdot \mathrm{kPa})^{-1}$ and $\mathrm{E} / \mathrm{P}$ has the units of $\mathrm{Kv}(\mathrm{cm} \cdot \mathrm{kPa})^{-1}$.

For a given $\mathrm{SF}_{6}$-gas mixture, the effective ionization coefficient is assumed to be given by:

$$
(\dot{\alpha} / \mathrm{P})_{\text {mix }}=\mathrm{F}(\dot{\alpha} / \mathrm{P})_{\mathrm{SF}_{6}}+(1-\mathrm{F})(\dot{\alpha} / \mathrm{P})_{\mathrm{gas}}
$$

Where, $\mathrm{F}=\mathrm{P}\left(\mathrm{SF}_{6}\right) / \mathrm{P}($ mix $)$ is the partial pressure ratio of the $\mathrm{SF}_{6}$ component in a given gas mixture.

When added two electronegative gases to $\mathrm{SF}_{6}$-gas mixture, the effective ionization coefficient is assumed to be given by :

$$
(\dot{\alpha} / \mathrm{P})_{\text {mix }}=\mathrm{F} 1(\dot{\alpha} / \mathrm{P})_{\mathrm{SF} 6}+\mathrm{F} 2(\dot{\alpha} / \mathrm{P})_{\mathrm{gas} 1}+\mathrm{F} 3(\dot{\alpha} / \mathrm{P})_{\mathrm{gas} 2}
$$

where, $\mathrm{F}_{1}=\mathrm{P}\left(\mathrm{SF}_{6}\right) / \mathrm{P}(\mathrm{mix})$ is the partial pressure ratio of the $\mathrm{SF}_{6}$ component in a given gas mixture, $F_{2}=\mathrm{P}\left(\operatorname{gas}_{1}\right) / \mathrm{P}(\mathrm{mix})$ is the partial pressure ratio of the first electronegative gas in a given gas mixture and $\mathrm{F}_{3}=\mathrm{P}\left(\mathrm{gas}_{2}\right) / \mathrm{P}(\mathrm{mix})$ is the partial pressure ratio of the second electronegative gas in a given gas mixture.

\section{Methodology for Breakdown Voltage Calculations}

In order to study the breakdown voltages for a fixed particle which is represented by a hemi-spherical tip with diameter (2r) and length (L) which is contaminating a parallel-plane gap with spacing $(\mathrm{G})$ for $\mathrm{SF}_{6}$ - gas mixture under $\mathrm{DC}$ voltage. The electric field around this fixed particle is satisfied in this work by using finite element method. With an applied electric field, discharges in the gas occur as a result of ionization, which lead to streamer formation and ultimately to breakdown of the gas mixture. One way to predict breakdown voltage of the gas mixture is, therefore, by knowing its effective ionization coefficient.

In a non-uniform field gap, corona discharges will occur when the conditions for a streamer formation in the gas are fulfilled. Streamer formation is both pressure and field dependent, and therefore depends on the electrode profile, geometry of the contaminating particle, its position in the gap between electrodes if it is free, and on the instantaneous value of the ambient field. The condition for streamer formation is given by;

$$
\int_{0}^{x_{c}} \bar{\propto}(x) d x \geq K
$$


Where, $\alpha(\mathrm{x})=\alpha(\mathrm{x})-\eta(\mathrm{x}), \alpha(\mathrm{x})$ and $\eta(\mathrm{x})$ are the first ionization coefficient and the coefficient of attachment, respectively; both being functions of field and thus of geometry.

The distance $\mathrm{xc}$ from the particle's tip is where the net ionization is zero, normally known as the ionization boundary. There is some controversy over the value of $\mathrm{K}$, the discharge constant. The value of $\mathrm{K}$ for pure gases in the pressure range of 100 to $400 \mathrm{kPa}$ is obtained as follows using the breakdown data given in CIGRE paper [17];

$\mathrm{K}$ for pure $\mathrm{N}_{2}$ is $(5 \pm 0.5)$. Malik and Qureshi [18] assumed that $\mathrm{K}$ has a value in between 5 and 25 for the different $\mathrm{SF}_{6}$ gas mixtures. In this study for breakdown voltages we take the value of $\mathrm{K}=18.42$ for $\mathrm{SF}_{6}$ gas and $\mathrm{SF}_{6}$ - gas mixture but $\mathrm{K}=5$ for $\mathrm{N}_{2}$ gas and $\mathrm{K}=27$ for $\mathrm{CO}_{2}$ gas.

\section{Breakdown Voltage Results for Gas Mixtures with Particle Contamination}

A. Effect of Gas Pressure on the Breakdown Voltage

The effect of fractional concentration of $\mathrm{SF}_{6}$ gas in mixture under different gas pressure with particle contamination is shown in Figures. 15, 16 and 17. From these figures we can see that, if the fractional concentration of $\mathrm{SF}_{6}$ increase in mixture, the breakdown voltage is also

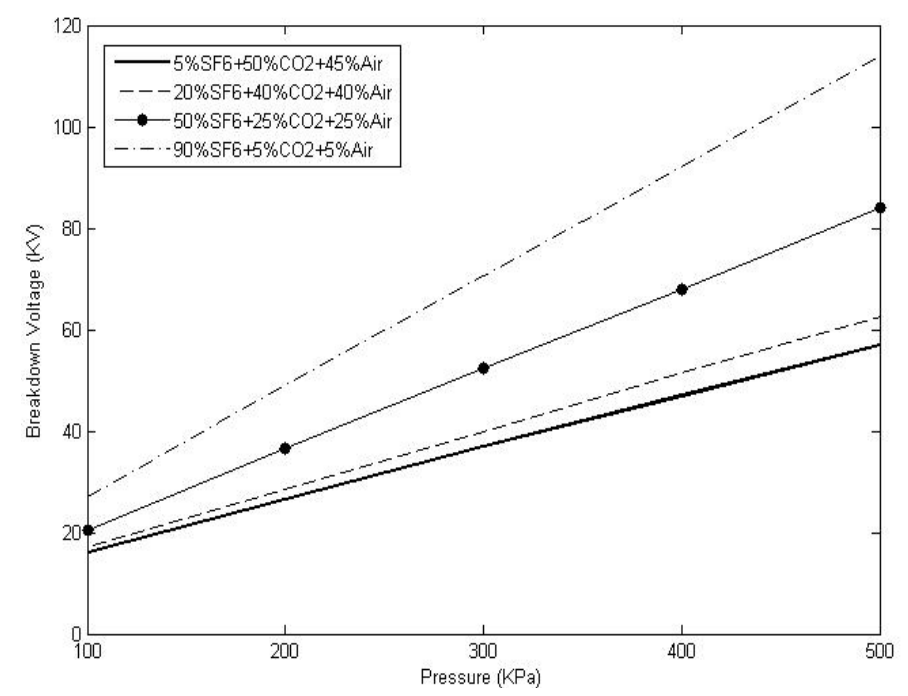

Figure 15. Effect of gas pressure for $\mathrm{SF}_{6}: \mathrm{CO}_{2}$ :Air mixture on BreakdownVoltage for a gap with particle contamination

increased. Also, the breakdown voltage for mixture is increased as the pressure of mixture increases. From Figure 15, it can be observed that as fractional concentration of $\mathrm{SF}_{6}$ gas in mixture increases, breakdown voltage increases but as fractional concentration of $\mathrm{CO}_{2}$ \& Air gases decreases in mixture, breakdown voltage increases. From Figure 16, it can be observed that as fractional concentration of $\mathrm{N}_{2} \&$ Air gases decreases in mixture, breakdown voltage increases. From Figure 17 at fixed percentage of $\mathrm{SF}_{6}$ gas in mixture, increasing percentage of $\mathrm{N}_{2}$ gas and decreasing percentage of Air in the same mixture increasing the breakdown voltage, we note that breakdown voltage for $\left(5 \% \mathrm{SF}_{6}+80 \% \mathrm{~N}_{2}+15 \%\right.$ Air $)$ is greater than $\left(5 \% \mathrm{SF}_{6}+5 \% \mathrm{~N}_{2}+90 \%\right.$ Air) by $22.2 \%$. Also at fixed percentage of $\mathrm{SF}_{6}$ gas in mixture, increasing percentage of $\mathrm{CO}_{2}$ gas and decreasing percentage of Air in the same mixture increasing the breakdown voltage, we note that breakdown voltage for $\left(5 \% \mathrm{SF}_{6}+80 \% \mathrm{CO}_{2}+15 \%\right.$ Air $)$ is greater than $\left(5 \% \mathrm{SF}_{6}+5 \% \mathrm{CO}_{2}+90 \%\right.$ Air $)$ by $12.6 \%$. 


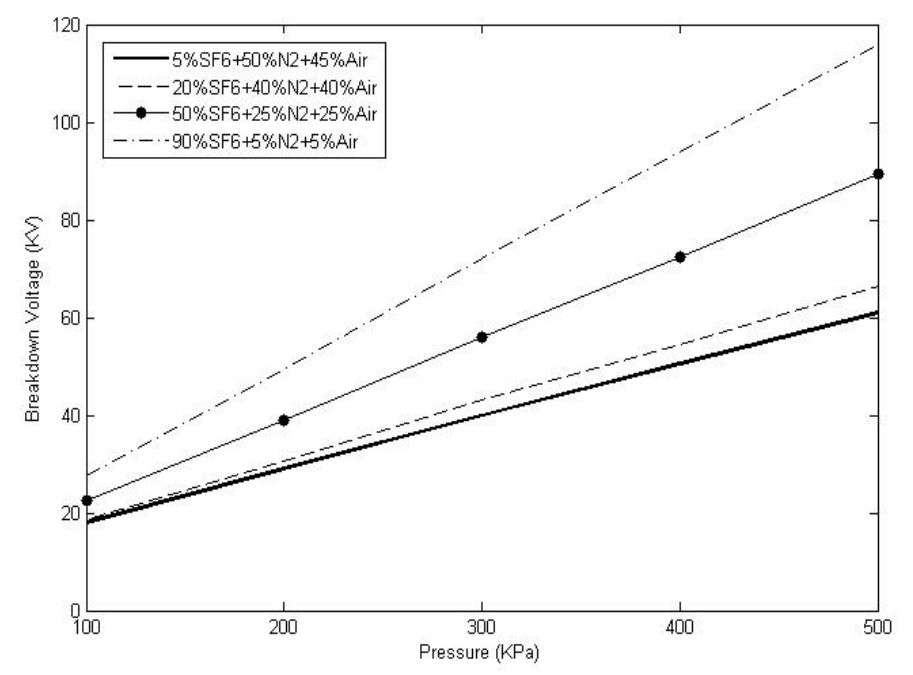

Figure 16. Effect of gas pressure for $\mathrm{SF}_{6}: \mathrm{N}_{2}$ :Air mixture on BreakdownVoltage for a gap with particle contamination

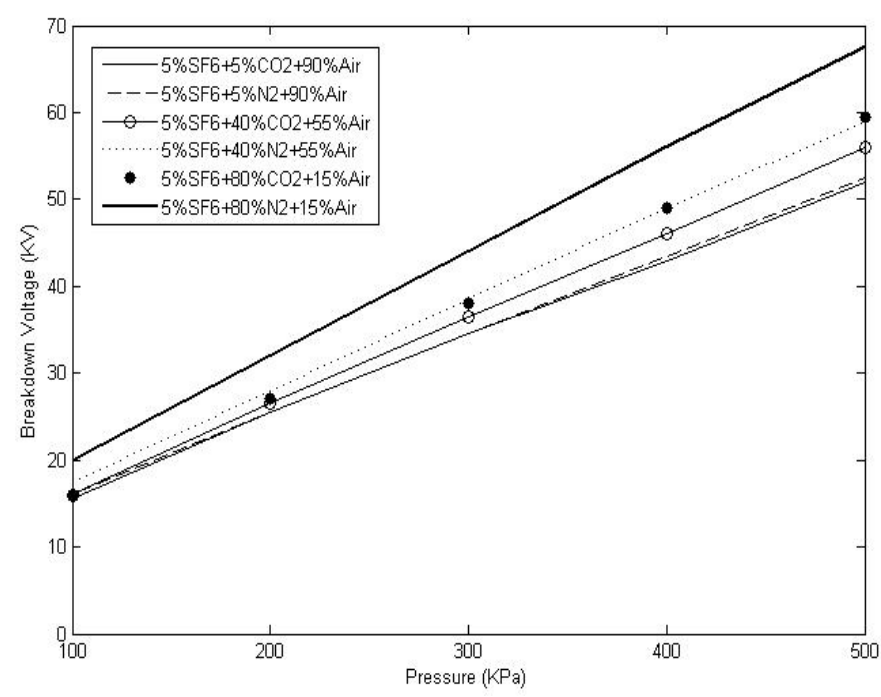

Figure 17. Effect of gas pressure for $5 \% \mathrm{SF}_{6}$-gas mixture on BreakdownVoltage for a gap with particle contamination

B. Effect of Gap Spacing Between Two Parallel Plates onBreakdown Voltage

From Figures 18 and 19, If fractional concentration of $\mathrm{SF}_{6}$ gas increased in mixture with decreasing percentage of $\mathrm{N}_{2}$ or $\mathrm{CO}_{2}$ gas and also decreasing percentage of Air gas in the same mixture, hence the breakdown voltage increases. 


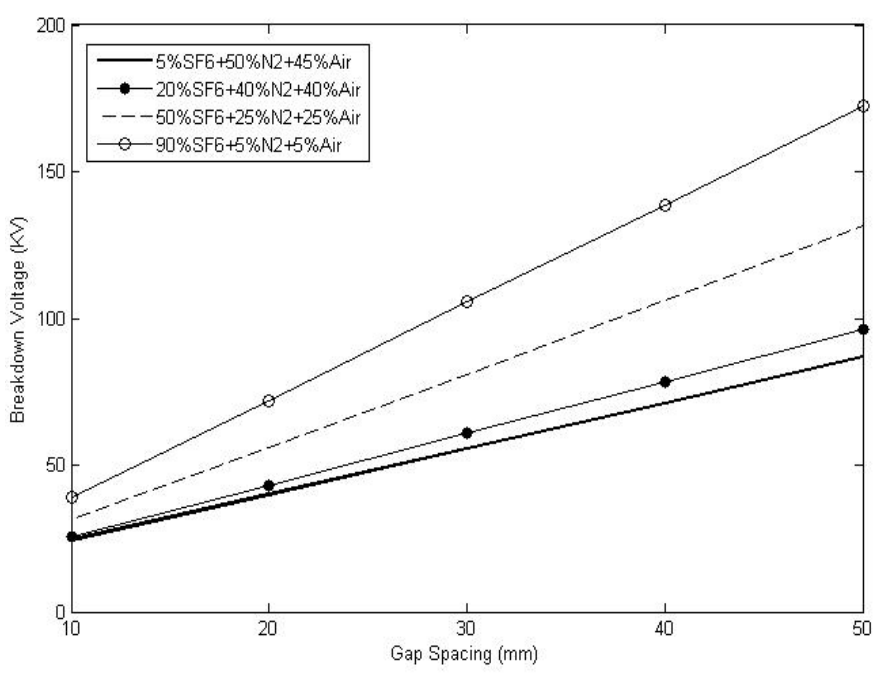

Figure18.Effect of gap spacing on Breakdown Voltage forSF ${ }_{6}: \mathrm{N}_{2}$ :Air gas mixture at $\mathrm{P}=300 \mathrm{KPa}$

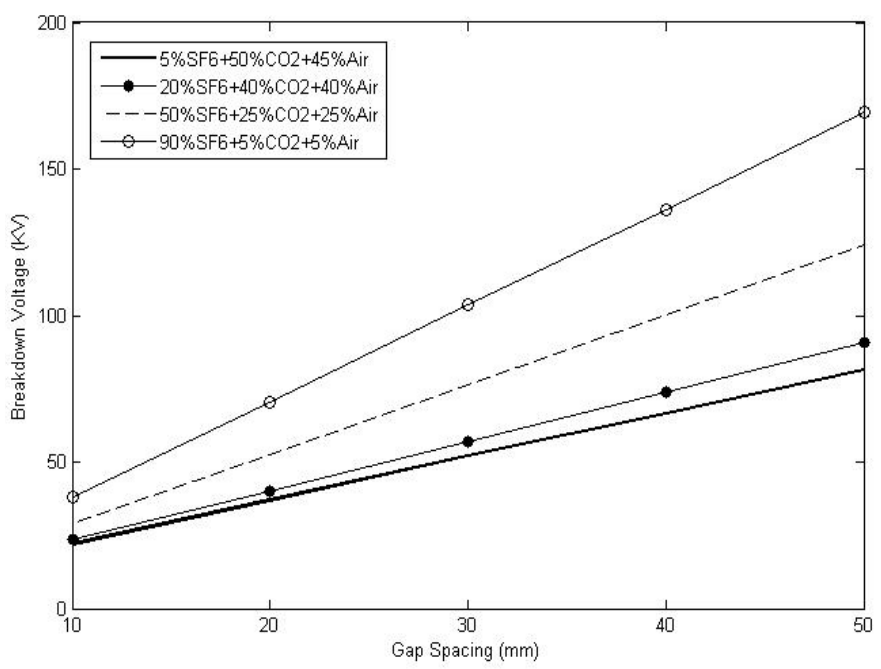

Figure 19.Effect of gap spacing on Breakdown Voltage forSF $6 \mathrm{CO}_{2}$ : Air gas mixture at $\mathrm{P}=300 \mathrm{KPa}$

\section{Effect of the Dimensions for Particle Contamination on Breakdown Voltage}

The effect of particle dimensions (particle radius and particle length) on the breakdown voltage for $\mathrm{SF}_{6}$-gas mixture with different concentration of $\mathrm{SF}_{6}$ in mixture is shown in Figures 20 and 21. From Figure 20, as hemispherical radius of particle increases, the breakdown voltage increases and also as fractional concentration of $\mathrm{SF}_{6}$-gas in mixture increases, the breakdown voltage increases. From Figure 21, as particle length increases, the breakdown voltage decreases but as fractional concentration of $\mathrm{SF}_{6}$-gas in mixture increases, the breakdown voltage increases also. 


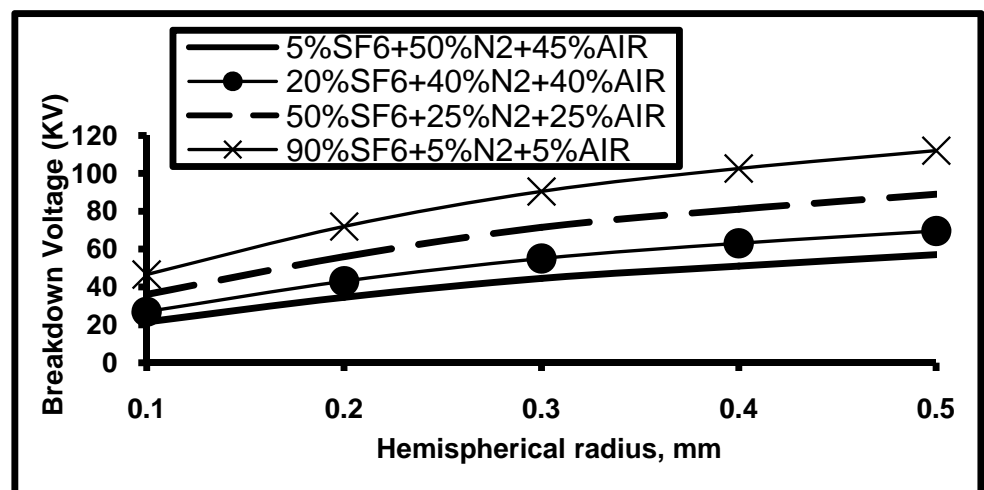

Figure 20.Effect of hemispherical radius of particle on Breakdown Voltage for $\mathrm{SF}_{6}: \mathrm{N}_{2}$ :Airgas mixture at $\mathrm{P}=300 \mathrm{KPa}$

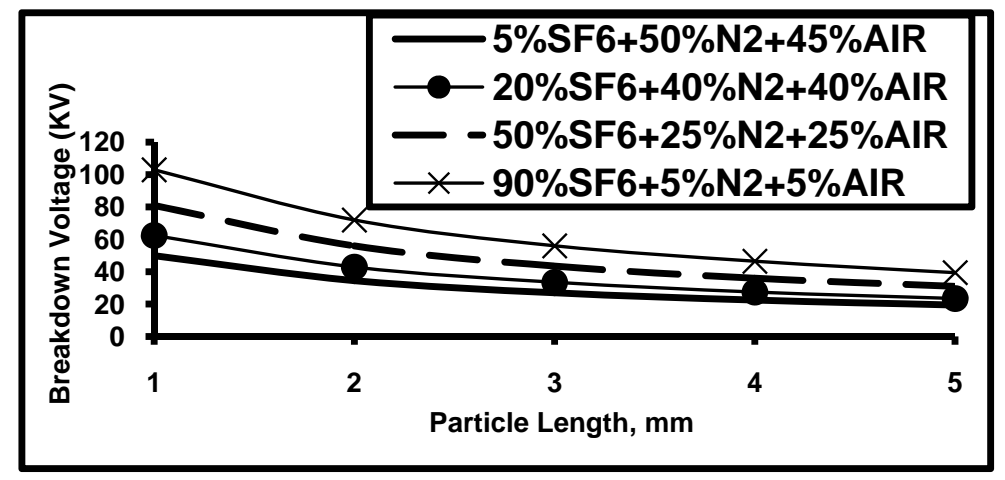

Figure 21.Effect of particle length on Breakdown Voltage for $\mathrm{SF}_{6}: \mathrm{N}_{2}$ :Air gas mixture at $\mathrm{P}=300 \mathrm{KPa}$

\section{Comparison between Breakdown Voltage for Gap with particlecontamination and clean gap}

Figure 22 shows the difference between breakdown voltage in case of clean gap compared with breakdown voltage in case of presence of particle contamination in the gap with $L=2 \mathrm{~mm}$ and $\mathrm{r}=0.2 \mathrm{~mm}$ and also shows the effect of gas pressure on breakdown voltage for various fractional concentration of $\mathrm{SF}_{6}$ gas in mixture in case of clean gap and also with particle contamination. At $\mathrm{P}=500 \mathrm{KPa}$ and $\mathrm{G}=20 \mathrm{~mm}$, the breakdown voltage in case of clean gap for $\mathrm{SF}_{6}-\mathrm{N}_{2}$ gas mixture with $5 \% \mathrm{SF}_{6}$ concentration is $460 \mathrm{KV}$ but in case of gap with particle contamination, the breakdown voltage is $71.5 \mathrm{KV}$, i.e breakdown voltage for gap with particle contamination decreases approximately by $15.5 \%$ from it's value in case of clean gap. 


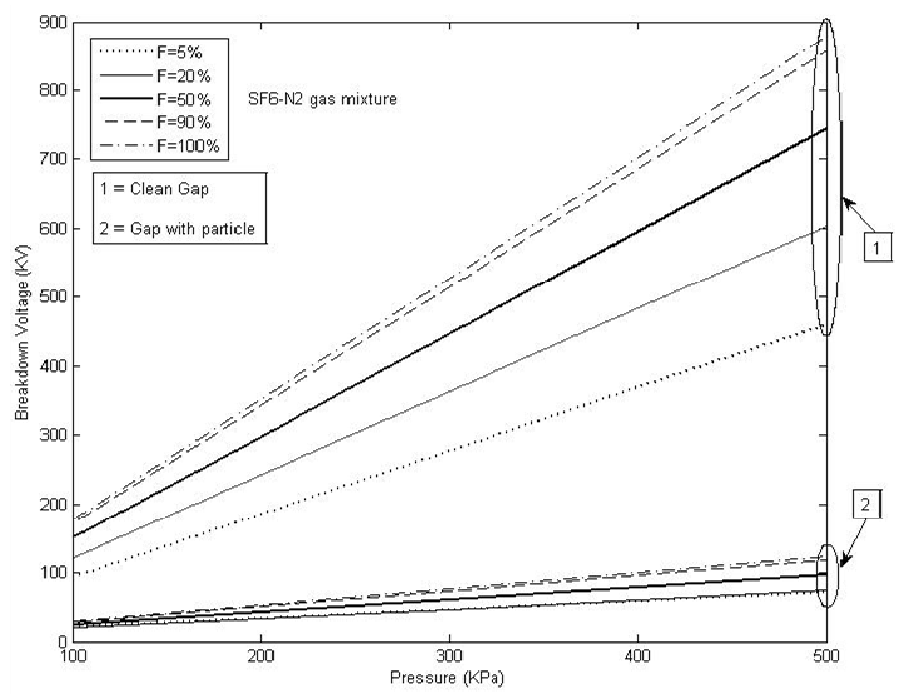

Figure 22. Effect of gas pressure on breakdown voltage for clean gap and gap with particlecontamination for a various fractional concentrations of $\mathrm{SF}_{6}-\mathrm{N}_{2}$ gas mixture

\section{Conclusions}

In this study, two electrostatic modeling which consists of two parallel plates with earthed particle and other with hovering particle are presented. The electric field at upper tip of the wire particle increases as the particle length increases and decreases as the wire particle radius increases. The electric field is maximum at upper tip and lower tip of the hovering wire particle and minimum at the middle of particle surface. The breakdown voltage increases as fractional concentration of $\mathrm{SF}_{6}$ gas increases in mixture and also with increasing the pressure of mixture. At fixed percentage of $\mathrm{SF}_{6}$ gas in mixture, with increasing the percentage of $\mathrm{N}_{2}$ gas and decreasing the percentage of Air in the same mixture, the breakdown voltage increases, the breakdown voltage for $\left(5 \% \mathrm{SF}_{6}+80 \% \mathrm{~N}_{2}+15 \%\right.$ Air $)$ gas mixture is greater than that for $\left(5 \% \mathrm{SF}_{6}+5 \% \mathrm{~N}_{2}+90 \%\right.$ Air) gas mixture by about $22.2 \%$. At fixed percentage of $\mathrm{SF}_{6}$ gas in mixture, with increasing the percentage of $\mathrm{CO}_{2}$ gas and decreasing the percentage of Air in the same mixture, the breakdown voltage increases, the breakdown voltage for $\left(5 \% \mathrm{SF}_{6}+80 \% \mathrm{CO}_{2}+15 \%\right.$ Air) gas mixture is greater than that for $\left(5 \% \mathrm{SF}_{6}+5 \% \mathrm{CO}_{2}+90 \%\right.$ Air) gas mixture by about $12.6 \%$. The breakdown voltage increases as the hemispherical radius of the particle increases, while it decreases as the particle length increases. At $\mathrm{P}=500 \mathrm{kPa}, \mathrm{G}=20 \mathrm{~mm}$, $\mathrm{L}=2 \mathrm{~mm}$ and $\mathrm{r}=0.2 \mathrm{~mm}$ for $5 \% \mathrm{SF}_{6}-\mathrm{N}_{2}$ gas mixture, the breakdown voltage for gap with particle contamination decreases approximately by $15.5 \%$ from it's value in case of clean gap Finally, it can be concluded that the probability of breakdown voltage for gap with particle contamination is greater than that for clean gap.

\section{References}

[1]. Sayed A. Ward, " Optimum $\mathrm{SF}_{6}-\mathrm{N}_{2}, \mathrm{SF}_{6}$-Air, $\mathrm{SF}_{6}-\mathrm{CO}_{2}$ Mixtures Based on Particle Contamination ", Conference Record of the 2000 IEEE International Symposium on Electrical Insulation, Anaheim, CA USA, pp.292-295, 2000.

[2]. M.M. Morcos, S. Zhang, K.D. Srivastava, " Mangement of Particle Contamination in GIS/GITL by Electrode Coating", CIGRÉ, Paper 15-401, 2002.

[3]. M.M. Morcos, S.A. Ward, H. Anis, K.D. Srivastava and S.M. Gubanski, "Insulation Integrity of GIS/GITL Systems and Management of Particle Contamination", IEEE Electrical Insulation Magazine, Vol. 16, No. 5, pp.25-37, 2000. 
[4]. W. Pfeiffer, D. Schoen, " Requirements for Gaseous Insulation for Application in GITL Considering $\mathrm{N}_{2}, \mathrm{~N}_{2} \mathrm{O}$ and $\mathrm{CO}_{2}$ with Low Content $\mathrm{SF}_{6}$ ", Conference Record of IEEE International Symposium on Electrical Insulation, Indianapolis, IN USA, pp.536-539, 2004.

[5]. Sayed A. Ward, " The Breakdown Voltages for Compressed Gas-Insulated Systems with Contamination Considering the Space Charge Effect", Conference Record of IEEE International Symposium on Electrical Insulation, Montreal, Quebec, Canada, pp.87-90, 1996.

[6]. Sayed A. Ward, "Influence of Conducting Particles on the Breakdown Voltages of $\mathrm{SF}_{6}-\mathrm{N}_{2}$ mixture", High Voltage Engineering Symposium, Conference Publication No. 467, IEE, pp.187-192, 1999.

[7]. H.R. Hiziroglu, J.Griggs, M.S.Dincer, "Breakdown Voltages in Argon+SF 6 Mixtures Subjected to Impulse Voltages ", Annual Report, Conference on Electrical Insulation and Dielectric Phenomena, IEEE, pp.786-788, 2002.

[8]. Hitoshi Okubo, Naoto Koshino, Naoki Hayakawa, "Electrical insulation characteristics of $\mathrm{CO}_{2}$ and $\mathrm{CO}_{2}$ gas mixtures under non-uniform electric field", Annual Report Conference on Electrical Insulation and Dielectric Phenomena, IEEE, pp.538-541, 2003.

[9]. H.Saitoh, K.Morita, T.Kikkawa, N.Hayakawa, H.Okubo, "Impulse Partial Discharge and Breakdown Characteristics of Rod-plane Gaps in $\mathrm{N}_{2} / \mathrm{SF}_{6}$ gas mixtures", IEEE Transactions on Dielectrics and Electrical Insulation, Vo1.9, N0.4, pp.544-550, 2002.

[10]. Y. Hoshina, M. Sato, M. Shiiki, M. Hanai, E. Kaneko,"Lightning impulse breakdown characteristics of $\mathrm{SF}_{6}$ alternative gases for gas-insulated switchgear", IEE Proc.-Sci. Meas. Technol., Vol. 153, No. 1, pp.1-6, 2006.

[11]. Masayuki Hikita, Shinya Ohtsuka, Shigemitsu Okabe, Shuhei Kaneko, "Insulation Characteristics of Gas Mixtures including Perfluorocarbon Gas", IEEE Transactions on Dielectrics and Electrical Insulation, Vol. 15, No.4, pp.1015-1022, 2008.

[12]. David Meeker, "Finite Element Method Magnetics, Version 4.2, User's Manual", September 2006.

[13]. N. H. Malik, A. H. Qureshi, "A review of electrical breakdown in mixtures of $\mathrm{SF}_{6}$ and other gases", IEEE Transaction on Electrical Insulation, Vol. EI- 14, No. 1, pp. 1-13, 1979.

[14]. A Rein, " Breakdown mechanisms and breakdown criteria in gases: Measurement of discharge parameters. A literature survey", Bioctra, No. 32, pp. 43-60, 1974.

[15]. S. Berger, "Onset of breakdown voltage reduction by electrode surface roughness in air and SF6", IEEE Trans. on PAS, Vol. PAS-95, No. 4, pp. 1073-1079, 1976.

[16]. N. H. Malik and A. H. Qureshi, "Breakdown mechanisms in sulphur-hexafluoride", IEEE Trans. on Elect. Insul., Vol. EI-12, No. 3, pp. 135-145, 1978.

[17]. T. w. Dakin, G. Luxa, G. Oppermann, J. Vigreux, G. Wind, H. Winkeln- Kemper, "Breakdown of gases in uniform fields, Paschen curves for nitrogen, air and sulphurhexaflouride", Electra. CIGRE Paper No.32, pp.64-70, 1974.

[18]. N. H. Malik, A. H. Qureshi, "Breakdown gradients in $\mathrm{SF}_{6}-\mathrm{N}_{2}, \mathrm{SF}_{6}$-Air and $\mathrm{SF}_{6}-\mathrm{CO}_{2}$ mixtures", IEEE Transaction on Electrical Insulation, Vol. EI- 15, No. 5, pp. 413-418, 1980. 


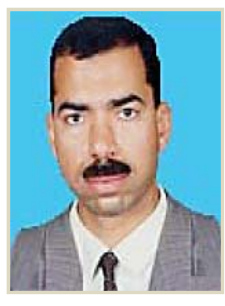

Sayed A. Ward was born in Cairo, Egypt, on December 24, 1961. He received the B.Sc. degree in electrical engineering with honor in 1984 and the M.Sc. degree in high-voltage Engineering in 1988, both from Zagazig University, Shoubra, Cairo, Egypt. He received the Ph.D. degree in highvoltage engineering in 1992 from Cairo University. He is currently a professor with the Electrical Engineering Department, Faculty of Engineering (Shoubra), Cairo, Egypt. His research activity includes studying the gas discharge phenomena in GIS, breakdown voltage study in GIS systems for compressed gases and gas mixtures. Also his research activity includes breakdown in Insulating Oils and DGA oil analysis in power transformers.

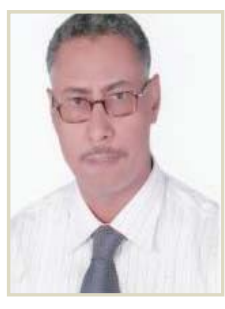

Mousa A. Abd-Allah was born in Cairo, Egypt, on August 16, 1961. He received the B.Sc. degree in electrical Engineering with honor in 1984 and the M.Sc. degree in High Voltage Engineering in 1988, both from Zagazig university, benha branch, Cairo, Egypt. He received the Ph.D. degree in High Voltage Engineering in 1992 from Cairo university. He is currently a professor with the Electrical Engineering department, Faculty of Engineering at Shoubra,Benha university. His research activity includes Electromagnetic Field Assessment and Mitigation around Electrical Equipments, Gas discharge in gas insulated systems, Electromagnetic Compatibility, Transient Phenomenon in Power Networks.

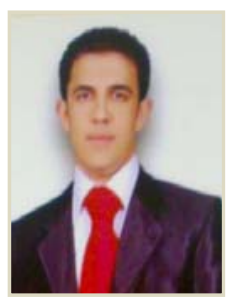

Amr A. Youssef was born in Cairo, Egypt, on July 31, 1985. He received the B.Sc. degree in electrical engineering with honor degree in 2007 from Faculty of Engineering at Shoubra, Benha University, Cairo, Egypt. On December 2008, he received his work in this faculty as an instructor in the Electrical Engineering Department. In 2011, he will receive the M.Sc. degree in electrical engineering from this faculty. Currently he is an assistant lecturer at Electrical Engineering Department in this faculty and also PH.D researcher in high voltage engineering.His research activity includes studying the characteristics of various gas mixtures, electric field and breakdown voltage calculations around single and multi-contaminating particles inside GIS and GITL. 